\title{
The Psychological Impact of Discrimination on the Mental Health of Egyptian Christian Students
}

\author{
By Monir F. Morgan ${ }^{* 1}$
}

\begin{abstract}
Egyptian Christian students in K-12 school settingsare negatively stereotyped based on an assumed range of activities, characteristics, or behaviors. They are discriminated against and treated less favorably by radical Egyptian Muslim students, teachers, and administrators on the grounds of their ethnic and religious background. Literature suggests that the frequency of perceived discriminatory practices results in negative health outcomes. This qualitative study is the first of its kind to investigate the relationship between ethnic and religious discrimination and well-being in the Egyptian K-12 school settings. Focus group discussions and key informants' interviews were used in an attempt to reach an in-depth understanding of Egyptian Christians students' lived experiences with discriminationin the Egyptian K-12 school settings. The analysis of the relevant constructed meanings that emerged from the discussions and interviews shows that Egyptian Christian students in the Egyptian K-12 school settings suffer from daily individual, institutional, and structural discrimination. Such discrimination is manifested in discriminatory educational practices and policies, curriculum and textbook, daily interactions, and school environment and results in many untreated mental health problems.
\end{abstract}

Keywords: Discrimination, Discriminatory educational practices, Mental well-being, Multicultural education.

\section{Introduction}

We witness serious and distressing expressions of prejudice, racism, discrimination, and related intolerance in different countries and in different settings. In many countries, ethnic and religious minorities are subjected to individual, institutional, and structural discrimination represented in daily prejudice, injustice, stereotyping, and micro and macro aggressions. According to Kottak (2000), the historical, social, economic, political, cultural, or religious injustice, discrimination, prejudice, and stereotyping minority groups are the main sources of ethnic conflicts around the world. Morris (2011) indicates that stereotyping for various reasons continues to be alive and is seemingly engrained in the human psyche. Discrimination refers to differential behavioral acts, ranging from exclusion to physical assault, that disadvantage an individual or group based on social group membership (Brown and Bigler 2005, Gee et al. 2009). Perceived everyday discrimination has been conceptualized in terms of routine behaviors, such as receiving poorer service, being treated with less courtesy and less respect, and being called names (Williams, Yu, et al. 1997).

\footnotetext{
*Assistant Professor, Alvernia University, USA.

${ }^{1}$ The author is also known as Monir F. Atta-Alla in previous publications
} 
A growing body of research shows that discriminatory practices and policies toward racial, ethnic, and religious minorities have been and continue to be of great concern (Byrd and Mirken 2011, Lewis et al. 2015). Discrimination could be a public health problem (Kaholokula et al. 2012, Mossakowski et al. 2017). Discrimination can be manifested in different forms such as, (a) "stereotypes", which are generalizations about a social group that are often linked to experiences of discrimination (Brown and Bigler 2005), (b) "prejudice", which is a predetermined judgment or bias based on one's social group membership, an unfair negative attitude toward a social group or a member of that group, and looking down on - a group because of its assumed behavior, values, abilities, or attributes (Dovidio and Gaertner 2000, Fiske 1998, Kottak 2000), (c)"racial micro aggressions", which often take the form of interpersonal slights based on common stereotypes (Cheryan and Monin 2005, Sue et al. 2007 ).

Discrimination is linked with negative mental health outcomes (e.g., anxiety, depression, and negative self-esteem, distress, hopelessness, loneliness, psychological distress, social and emotional difficulties, stress, suicide, etc.). Literature on the relationship between discrimination and mental health has emphasized that continued discrimination toward racial, ethnic, and religious minorities results in psychological, physiological, and psychosocial distresses (Guyll et al. 2001, Meyer 2003a, Schulz et al. 2000, Williams et al. 1999) and negatively influences their academic achievement (Banks and Banks 2010, Gay 2010, Taylor and Whittaker 2009). Discrimination has also been found to be associated with significantly more and higher psychological distress (Kessler et al. 1999, Williams, Watts et al. 1997). Reported experiences of prejudice and discrimination are related to greater levels of psychological distress (Klonoff et al. 1999, Landrine and Klonoff 1996, Utsey and Ponterotto 1996). Reviews on discrimination and health have documented strong and consistent links between self-reported experiences of discrimination and a variety of indicators of mental health and psychological well-being (Greene et al. 2006, Huynh and Fuligni 2010, Paradies 2006a, Pascoe and Smart Richman 2009, Schmitt, et al. 2014, Williams and Mohammed 2009). Racial, ethnic, and religious minorities suffer from poorer mental and physical health than their majority counterparts (Adler and Rehkopf 2008, Williams and Mohammed 2009, Williams et al. 2003). Research findings also showed that direct or vicarious discrimination has negative impact on the health and mental well-being of children and young people (e.g., Coker et al. 2009, Kelly et al. 2012, Nyborg and Curry 2003, Pachter and Garcia Coll 2009, Paradies 2006b, Priest et al. 2010, Sanders-Phillips 2009, Simons et al. 2002, Szalacha et al. 2003, Williams and Mohammed 2009). Pertinent literature indicates that experiences of individual, institutional, and/or structural discrimination negatively impact children and young people's well-being and negatively affect their development and adjustment, with potential consequences throughout the life course (Mays et al. 2007, Sanders-Phillips 2009). Brown and Bigler (2005) point out that when children and adolescents perceive themselves as a target of discrimination, commonly in terms of being excluded or being called names, can harm their identity formation, peer relations, and physical and mental well-being.

Egypt is one of the countries, where religious and ethnic minorities like Copts 
(Egyptian Christians) continuously face different types and forms of discrimination. The discriminatory policies in all facets of life including education against minorities, particularly Christians in Egypt have resulted in mass exodus. Heikal (2000) states, "There is a migration phenomenon among Copts that we should not ignore. We should neither overlook its causes, even if they were psychological "(p. 14). The name 'Egypt' is derived from the Greek word Aegyptos. Egypt was essentially a Christian country for the first six centuries. Atta-Alla (2008) states that when the Arabs invaded Egypt in 641 AD, they called the Egyptians "Qipt", "Gibt", or "Gypt". They use the word Qipt, Gibt, or Gypt to mean both Egyptians and Christians. The modern use of the term "Copts" describes Egyptian Christians. According to the Central Bureau of Statistics and Mobilization (October, 2017), Egypt's population reached 104 million, becoming the 13th largest in the world, Copts (Egyptian Christians) form almost $22 \%$ to $25 \%$ of the population. The culture of modern Egypt includes a variety of live traditions that remain from the time of the Pharaohs, as well as those that were brought in by the many invaders throughout the centuries. Atta-Alla (2008) states, "Contemporary Egyptian culture is a mixture of a multitude of elements, shaped by the progression of historical events, which has contributed to the development of Egypt's current atmosphere" (p. 114). Copts, who are the indigenous people of Egypt, have their own ways of thinking, believing, feeling, and acting that constitute their unique minority group culture. Their culture is a major component of their identities within a framework of their social cohesion. Atta-Alla (2012) points out that although Copts are integrated into the body of the Egyptian nation, they experience the three forms of discrimination: individual, institutional, and structural because they can be easily distinguished. Most Christian men and women have a cross tattooed on the inside of the right wrist. Names also distinguish Muslims from Christians. Muslims have Arab and Islamic names and Christians have biblical or secular Egyptian names.

Egypt education system should reflect the nature of the Egyptian pluralistic multicultural society. It is supposed to allow all minority group students to proclaim their identities without coming into conflict with the majority population. However, the Egyptian government and the radical Egyptian Muslims generally neglect and marginalize the Coptic culture in different settings including school settings. They consider it the culture of a minority group that lives in the shadow of the Muslim majority population who has different and dominant cultural ideology. As indicated by Shukrallah (1994), Islamist revivalist movement in Egypt has challenged the full participation of certain minority groups, including Christians. Religious minorities in Egypt continued to face significant threats of terrorist attacks and sectarian violence (International Religious Freedom Report for 2016). In spite of the continued and repeated request of President Abdel Fatah Al Sisi beginning June 2014 and the call of many liberaland moderate Muslim scholarsfor the renewal of religious discourse in Egypt, the revision and modification of the educational policies and curriculum as well as the retraining of teachers and administrators, nothing has happened yet.

Egyptian Christian students are always subject to continued discriminatory educational practices and policies that undermine the bases of their existence. These discriminatory educational practices and policies are represented in negative 
stereotyping, biases, prejudice, discrimination, and micro and macroaggressions by radical Egyptian Muslim majority students, teachers, and administrators. They are clearly manifested in the curriculum, textbooks, school environment, and classroom interactions. The discriminatory practices towards Egyptian Christian students in the Egyptian K-12 school settings vary considerably and include physical and psychological attacks, defamatory or erroneous textbooks used in public schools, negative stereotypes, and violation of due process rights. Such continued educational unjust and discriminatory practices and policies nullify and impair the Egyptian Christian students' recognition, enjoyment, and exercise of their human rights and radical freedoms in the social, cultural, educational and other dimensions of public life in their country. They are becoming social and psychological stressors that have negative impacts on the Egyptian Christian K-12 students' mental health.

\section{Methodology}

As stated before, many studies have investigated the mental health consequences of discrimination in different contexts and few studies have examined the mental health consequences of discrimination in school contexts (Tummala-Narra and Claudius 2013). In spite of the continued daily discrimination towards Egyptian Christians in general and Egyptian Christian students, in particular, there has been less attention to Christian students' experiences due to the little information available about the discriminatory practices and policies that they experience. Therefore, my study, which is the first to focus on Egyptian Christian students, aims to investigate the psychological impact of discrimination in the Egyptian K-12 school settings on the Egyptian Christian students' mental health.

\section{Research Questions}

The purpose of this qualitative study was to investigate the psychological impact of discrimination on the mental health of Egyptian Christian students. This study was designed to bring Egyptian Christian students of similar religious backgrounds together to create discourse around their perception of day-to-day discriminatory practices and policies in the Egyptian K-12 school settings. Consequently, the following three research questions drove the present study:

1. How do educational policies, curriculum, textbooks, and school environment discriminate against Christian students in the Egyptian K-12 school settings?

2. How do majority students, teachers, and administrators discriminate against Christian students in the Egyptian K-12 school settings?

3. How do the discriminatory educational policies, practices, and daily interactions in the Egyptian K-12 school settings impact Egyptian Christian students' mental health? 


\section{Sampling and Data Collection Protocol}

According to Patton (2002), sample size in qualitative research depends on the purpose of the research, what would be useful and credible, and the amount of time and resources that are available. "There are no rules for sample size" (p. 244). McCracken (1988) states that for qualitative methods the researcher should select a small sample, preferably fewer than eight participants. To increase the utility of information obtained from the participants of the present study, I used a purposive sample of 12 high school Egyptian Christian students (6 males and 6 females) who volunteered to discuss their lived experiences with discrimination in the Egyptian K-12 school settings. The participants were high school students attending the weekly youth meeting in one of the churches. They were enrolled in public Egyptian schools for 10 to 12 years.

In conducting the present qualitative study, I used four traditional qualitative methods of data-gathering, namely focus group discussion/interview, key informant interviews, researcher observations, and the researcher as an instrument. Focus group discussion/interview was selected as the main instrument of this study due to its unique capacity to provide participants the opportunities to react to each other, support each other, disagree with each other, and co-construct new understandings and shared meaning, which cannot be evidenced through individual interviews. It was used to engage the participants in a face-to-face dialogue regarding their lived experiences with discriminatory educational practices and policies in the Egyptian K-12 school settings. I used open-ended questions which led to further discussions among participants as well as further in-depth exploration of their lived experiences with discriminatory educational practices and policies. The focus group discussions that lasted 90 minutes were audiotaped and field notes were taken for data analysis.

In addition to the focus group interview, I conducted four individual interviews with key informants, two with female students and two with male students on a one-on-one basis. The four key informants were identified from the focus group discussion in light of their willingness to discuss their lived experience with discrimination in-depth. The purpose of conducting the four one-on-one individual interviews was to flesh out the richest possible data and to gain information that was not directly observable. These key informants' interviews that lasted from 24 to 40 minutes were also audiotaped to be used in data analysis. These interviews allowed me to build on the information presented in the focus group discussions and to come in greater contact with the perceptions, reflections, and meaning associated with participants' lived experiences with discriminatory educational practices and policies in the Egyptian K-12 school settings. I encouraged the key informants to provide insights regarding meanings attached to some major discriminatory practices and their psychological effects, which were described extensively during the focus group discussions, but were not fully addressed in terms of meanings attached to them. The information obtained from the key informants was triangulated against the data that was gathered through the focus group discussions to enhance the trustworthiness of the study results.

I also used my focused and unfocused observations as a method for collecting 
data for the present study. Patton (2002) argues that "to understand fully the complexities of many situations, direct participant observation in and observation of the phenomenon of interest may be the best research method" (p. 21). My focused and unfocused observations began forty years ago as an Egyptian Christian student in the Egyptian public schools and college. My observations enabled me to "become increasingly familiar with the insider's world so as to refine and focus subsequent observation and data collection" (Jorgensen (1989: 82), to identify the participants suited for the individual interviews, to become an instrument used to collect data about Egyptian Christian students' lived experiences with discriminatory educational practices and policies in the Egyptian K-12 school settings, and to triangulate and refine the data during the analytic process.

Moderating the focus group discussions and conducting the key informants' interviews, I used myself as one of the research instruments. This required me to be reflexive during the study. Therefore, I maintained an internal dialogue to explore what is known and how it is known (Berg 2007) and used field notes and a reflection journal. I also kept examining and reviewing my personal actions and reactions related to the study. In describing myself as a research instrument and a participant observer throughout the study, there is some obligation on my part to provide a more extensive description of who I am, and of my experiential background, so that the reader may form a context in which to situate the comments and the conclusions of this study. I was born and raised in Egypt as a Coptic (Egyptian) Orthodox Christian. I received my K-12 education and higher education in public schools and college. I studied in K-12 school settings where I experienced continued discrimination because of my ethnic and religious background. I grew up observing how Egyptian Christians experience daily individual, institutional, and structural discrimination.

\section{Focus Group and Key Informants'Interview Protocol}

The interview protocol included the following open-ended questions:

1. Describe the educational policies that made you feel discriminated against in the Egyptian K-12 school settings because of your ethnicity and religion.

2. Describe how school curriculum and textbooks discriminate against Christian students in the Egyptian K-12 school settings.

3. Describe how school environment discriminates against Christian students in the Egyptian K-12 school settings.

4. Describe when you felt uncomfortable, insulted, invalidated or disrespected by a comment that had ethnic and religiously-based discriminatory overtones in the Egyptian K-12 school settings.

5. Describe when other students, teachers, and administrators expressed stereotypical beliefs about your ethnicity and religion in the Egyptian K-12 school settings. 
6. Describe when other students, teachers, and administrators suggested or made you feel that you do not belong at the school because of your ethnicity and religion.

7. Describe the impact of the discriminatory educational policies and practices on your mental health and well-being.

Using open-ended questions in the focus group interview in this study allowed me to exercise some flexibility in addressing issues that were not anticipated before data collection and allowed the participants to choose the direction they wanted to respond from, provided them an opportunity to answer from a broader perspective, and gave them freedom to talk about their daily lived discrimination experiences. The participants in this study were able to answer most of the interview questions without formal prompts. In a few cases, I had to ask more specific open-ended questions and use some prompts to supplement the main questions of the interview protocol and encourage the participants to elaborate and give more details about their lived experiences with discrimination in their Egyptian K-12 school settings.

The focus group interview was digitally recorded. Using the semi-circle setting for the focus group discussion and asking the participants to respond to all questions in the same turn made it easy for me to observe the process and take field notes about each participant which were helpful throughout the data analysis stage. In addition to being an active listener throughout the discussions, I took field notes to supplement the interview transcripts (noting physical gestures or mannerisms), as well as documenting any early emerging themes that might lead to follow up on.

In using these questions during the focus group discussions/interviews and the key informants' interviews, I attempted to bracket my assumptions about Egyptian Christian lived experiences with discrimination. I kept in mind throughout the process of data collection, that bracketing assumptions is a continual process. In some interviews, when I was confronted with some life stories that did not fit with the assumptions I made about ethnic and religious discrimination, I stayed open to the participants' experiences and tried to understand such experiences.

\section{Data Credibility and Trustworthiness}

Although data retrieved from focus group are evidenced-based (Levers 2006), I took some measures to ensure the utility, validity, reliability, and trustworthiness of the study findings. Immediately following the focus group discussions, I documented my reflections on the interview process (how the interview went, my rapport, or something that could be improved for next time), as well as the topics discussed in the interview (both pre-planned topics, and topics or themes that emerged from the participants). In addition, I reflected at that time about how the participants' lived discrimination experiences and opinions either matched or contradicted my own, to minimize my bias. To accurately analyze the collected data, I constantly checked, rechecked, and built a solid foundation for the 
duration of the process of interpretation.

To enhance the relevance and credibility of the present study, I undertook several steps to support trustworthiness in this study. I used audio-taping, note taking, and observations to ensure accuracy in recording data. I used triangulation and member-checking techniques (Lincoln and Guba 1985) to enhance the credibility of the study. I established triangulation of data through using the digital audiotapes, notes, observations, review of related literature, and member checkins. Each of the main categories of themes emerged from the collected data was triangulated by confirming that data had been collected from different participants and through different methods (i.e., focus group interview session, memberchecking, and note taking). I used the field notes, which I took along with the focus group discussions and the key informants' interviews, to describe observations such as participants' body language, tone of voice, environmental distractions, contextual factors, changes in physical condition and comfort (Cohen et al. 2000).

To ensure research credibility or internal validity in this study, I did my best to remain adaptable and responsive during data collection and analysis. I also bracketed my assumptions, which were related not only to participants' responses but to the language they used. To protect the validity of the study results, I engaged myself in persistent observation, which required prolonged engagement in the material during data analysis methods (Lincoln and Guba 1985). The perpetual review of related literature has helped me to ensure the relevance of the research questions.

My experience as an Egyptian Christian student, who received his education in Egyptian public schools and college and suffered from similar discriminatory policies and practices contributed to my ability to think theoretically by providing a basic understanding of the participants' lived experience with ethnic and religious discrimination in the Egyptian K-12 school settings. With issues of trustworthiness and sensitivity in mind, actual data analysis became possible. To achieve the sensitivity of the study findings, I used the relevant literature and my personal experience to inform the analytic process.

\section{Data Analysis}

In analyzing the collected data and describing the units of meaning, I used Patton's (2002) reflexivity. The formal data analysis continued throughout the project until no new themes emerged from the data and until the emerged themes constitute an integrated description of the participants' lived experiences with ethnic and religious discrimination in the Egyptian K-12 school settings. I considered the analysis complete when I reached Glasser and Strauss's theoretical saturation (as cited in Rubin and Rubin 1995). That is when I was no longer able to identify more new themes. I compared my overall impressions to the initial codes that were noted throughout the research process, and I formulated the preliminary findings. Then, I compared these preliminary findings to the data with a final read through, with special attention paid to disconfirming evidence. After that, I used my earlier observations, my personal experiences, and the knowledge I 
have gained from the literature to reflect on the emerged units of meaning to entail the transformation of participants' everyday expressions into psychological language with emphasis on their lived experiences with the discriminatory educational policies and practices. Finally, I synthesized and integrated the insights contained in the transformed meaning units into a consistent description of the participants' lived experiences with discrimination. I used the cross analysis of the emerging themes and patterns in the focus group and key informants' interviews along with observations and the field notes to generate "thick descriptions" of the data, and thereby, of the lived experiences of the participants (Denzin and Lincoln 2000).

\section{Findings}

The emerged constructed meanings were organized under three major categories:

1. Perception of experienced discriminatory educational policies, curriculum, textbooks, and school environment,

2. Perception of experienced discrimination from majority students, teachers, and administrators, and

3. Impact of discriminatory educational policies, practices, and daily interactions on mental health.

Category I: Perception of Experienced Discriminatory Educational Policies, Curriculum, Textbooks, and School Environment

Research Question 1 asked, "How do educational policies, curriculum, textbooks, and school environment discriminate against Christian students in the Egyptian K-12 school settings?" The participants provided a few responses to the question to express their lived experience with discriminatory educational policies, curriculum, textbooks, and school environment. These responses are summarized as follows:

\section{Discriminatory Educational Policies}

The following examples are some of the most commonly described experiences by the participants in the focus group and key informants' interviews regarding the discriminatory educational policies in the Egyptian K-12 school settings:

1. Experiencing an Education system that reflects the Islamic nature of the state, omits secular knowledge in favor of religious beliefs, and focuses on passing along the heritage of Islamic knowledge, first and foremost through its primary sources, the Qur'an and the Sunnah. 
2. Experiencing an Education system that clearly reflects discriminatory educational policies, curriculum, pedagogy, school system, school atmosphere.

3. Being forced to follow discriminatory educational policies that impose a monocultural education system by focusing on Muslim majority culture and history.

4. Being forced to follow discriminatory educational policies that imply exclusive Islamic legislative interpretation of laws because the Islamic sharia is the major source of legislation.

5. Being forced to follow discriminatory educational policies that areboth institutional structural.

6. Experiencing discriminatory educational policies that insist on including religion as an identifying piece of information in all official school records, forms, and transcripts.

7. Experiencing discriminatory educational policies that discourage any openness towards others who have different cultural, social, ethnic, racial, or religious backgrounds.

8. Experiencing discriminatory educational policies that do not foster harmonious co-existence within and between majority and minority groups.

9. Experiencing educational policies created by radical Muslim policy makers who use their religious beliefs to create and use policies, general rules, and practices that do not allow Christian students and teachers to practice their cultural and religious differences.

10. Experiencing discriminatory educational policies mandating that the weekdays of schooling are Saturday through Thursday and Friday is the school weekend because it is the Muslim weekend in the whole Arab Muslim world.

11. Experiencing discriminatory educational policies that contribute to the segregation of Christian students.

The following are examples of what the participants shared in the focus group and key informants' interviews:

"In addition to the K-12 public schools that include both Muslims and Christian students, there is another public education system that includes Muslim students only. This education system is called the -Azharite education system. The graduates of this Islamic education system have the right to join Azharite University and become doctors, engineers, teachers, etc. Although these religious institutions are funded by our taxes, we do not have the right to join them."

"Forcing us to go to school on Sunday deprives us from going to the church. This is hurting and makes us feel the injustice and structural discrimination."

"They hold examinations during our Christian Holidays, feasts, and 
celebrations. When we try to protest, they make them immediately after our celebrations, I mean the day that follows our celebration. It is the same for us because we cannot enjoy our Christian Holidays, feasts, and celebrations since we must study for the exams."

"The Islamic names, places, events, and stories are included in most content area textbooks and we are forced to study them and get tested on them. We are also forced to study texts from the Quran (the Muslims Holy Book) and the sayings of the Islamic prophet, recite Islamic songs and slogans, and get tested on them."

"In my elementary school years, I experienced segregation and injustice during religious education lessons which are mandatory. Muslim students stay in the classrooms where they have a qualified Muslim teacher to teach them Islamic religious content and Christian students have the option to stay in class and learn the Islamic stuff or to go to the playground just to chat or play."

"At my high school, there are Muslim teachers (usually graduates of the Islamic Religious Azharite University). They are appointed by the Ministry of Education to teach religious education lessons to Muslim students. The teaching of religious education lessons to Christian students is usually delegated to unqualified Christian teachers at the school, who usually finds themselves reluctant and unprepared to teach such lessons."

\section{$\underline{\text { Discriminatory Curriculum and Textbooks }}$}

The following are examples of the most commonly described experiences by the participants in the focus group and key informants' interviews regarding the discriminatory curriculum and textbooks in the Egyptian K-12 school settings:

1. Experiencing a national K-12 curriculum that is not culturally or religiously pluralistic, not culturally relevant and responsive, and does not reflect the experiences of the diverse population of Egypt.

2. Experiencing a national K-12 curriculum that does not make room for teaching about minorities'culture, history, traditions, values, or views.

3. Experiencing a national K-12 curriculum that capitalizes only on the Muslim students' cultural and religious background and always attempts to override and negate Christian students' cultural and religious background,

4. Experiencing a national K-12 curriculum that does not promote intergroup harmony and increases conflict between Muslim students as a majority and Christian students as a minority,

5. Studying textbooks that are full of discriminatory evidences against Christian students and reflect the monocultural and Islamic education system, 
6. Studying textbooks that demotivate Christian students and hinder their academic success.

7. Studying textbooks that overlook the cultural and religious diversity of all learners, neglect the existence of indigenous Christians in the past and present and totally ignore their history and language.

The following are examples of what the participants shared in the focus group and key informants' interviews:

"The K-12 curriculum is intentionally planned to abolish the Christian identity from Egypt by mainly focusing on the Islamic images, history, culture, traditions, values, and characters. These images negatively influence our view of ourselves as a religious and ethnic minority."

"The majority of the textbooks reflect the Islamic nature of the society. They glorify and embellish the scientific discoveries of Arab Muslim scholars and philosophers, praise the golden age of Islam, and focus on the difference between the enlightenment of the golden age of Islam and the darkness in which westerners (Christians) were living in during the middle Ages."

"Throughout our K-12 schooling, we are forced to memorize the Quran and take exams on it through the lessons of the Arabic language textbooks, which are full of discrimination against Christian students and their religious beliefs."

"The textbooks are not culturally or religiously responsive to us as a religious and ethnic minority. They ignore the continuing contributions of Christians to the Egyptian society and their life."

"The textbooks and syllabi are mainly focusing on the Islamic history and the wars and victories of Mohammed, the Prophet of Islam. The history textbooks deliberately neglect whatever Coptic (e.g. the Coptic era, Coptic monasteries, ancient Coptic sites, churches, etc.). The Geography textbooks also deliberately neglect the Coptic Egypt. The Egyptian science textbooks don't include the contributions Christians made to science, and if it happens it is just the name of the Christian scientist without details. Even the Egyptian Mathematics textbooks always include Muslim names."

"K-12 Christian students are forced to memorize the Quran and take exams on it through the lessons of the Arabic language textbooks, which are full of discrimination against Christian students and their religious beliefs. Each lesson starts with a Quranic verse. Some lessons are suras (chapters) from the Quran, the Muslims' Holy Book. All names of people, places, incidents, etc. are Islamic names. The girls and women's pictures are Islamic; they are wearing the Islamic dress and hijab." 
"We do not feel comfortable studying materials in the textbooks that hinder our academic success because they do not see ourselves and our personal experiences reflected in the texts and images."

\section{Discriminatory School Environment}

The following examples are some of the most commonly described experiences by the participants in the focus group and key informants' interviews regarding the discriminatory school environment in the Egyptian K-12 school settings:

1. Being the only Christian student in the classroom, and activities, or games.

2. Being excluded from participating in group projects and social activities,

3. Experiencing racial jokes and teasing in a variety of school settings.

4. Overhearing ethnic and religious discriminatory conversations between students in the classroom.

5. Experiencing a supportive, positive, and learning stimulating atmosphere that focuses only on Muslim majority students.

6. Experiencing a school environment that develops and promotes a positive sense of self-esteem of the Muslim majority students and neglects Christian students.

7. Experiencing daily educational practices at schools that reflect the nature and goals of Egypt as an Islamic nation.

8. Experiencing a school environment that is not welcoming, not supportive, not inviting, and not empowering for Christian students.

9. Scheduling school-wide tests and project due dates on and around Christian religious occasions.

Here are some examples of what the participants shared in the focus group and key informants' interviews:

"The weekly school holiday is Friday, which is a sacred Islamic day. Sunday is a regular school day and we have to go to school on Sundays. The school year calendar is designed to reflect the Islamic holidays, celebrations and occasions. Our religious occasions are not included."

"The school day starts with the Quran and Christian students are obliged to listen to the Quranic and Hadith (Islam Prophet's speeches and sayings) readings and repeat them every day. Sometimes we are forced to listen to the curses and hatred directed to Christians and Jews. We do not have the right to respond or object."

"In the classroom, both the Islamic Basmala (Besm Allah Al-Rahman Al Raheem, which is -In the name of God, the Most Compassionate, and the Most Merciful) as well as the Islamic date are permanently written on the board and all students have to use them." 
"I feel as if I do not belong when I am the only Christian in class. I also feel uncomfortable in the playground because of my religion and ethnicity."

"I feel that my contributions in different learning contexts were minimized and that I was made to feel inferior because of my ethnic and religious background. Many Muslim students make me feel that I am not taken seriously in class because I am Christian."

"I've been in classes where people avoided sitting around me. Radical Muslim classmates don't talk to me and when it is time to gather in groups they seem to not want me in the group."

Category 2: Perception of Experienced Discrimination from Majority Students, Teachers, and Administrators

Research Question 2 asked, "How do majority students, teachers, and administrators discriminate against Christian students in the Egyptian K-12 school settings?" The participants of the present study provided a few responses to the question to express their perception of experienced discrimination from majority students, teachers, and administrators. The following are some of the most commonly described experiences:

1. Being stereotyped by radical Muslim students, teachers, and administrators based on an assumed range of activities, characteristics, or behaviors.

2. Hearing stereotypes in the content of lessons and other course materials,

3. Hearing inappropriate comments made by students, teachers, and administrators,

4. Listening to the perpetuation of unaddressed stereotypes during classroom discussions,

5. Receiving hostile reactions to participation in the classroom discussions,

6. Being assigned inferior status and social segregation that excludes them from meaningful interactions with the Muslim students in schools,

7. Experiencing injustice and deprivation of freedom of speech,

8. Experiencing segregation and humiliation,

9. Continuing to deliberately mispronouncing their Biblical or religious Christian names, even after correcting that several times,

10. Using inappropriate humor and jokes in class that degrade Christian students,

11. Hosting debates in class that place Christian students in a difficult position,

12. Singling Christian students out in class because of their ethnic and religious backgrounds,

13. Denying the experiences of the Christian students by questioning the credibility and validity of their responses,

14. Using discriminatory language, 
15. Assigning projects that ignore differences in cultural and religious backgrounds.

16. Ignoring complaints regarding discrimination in classroom and at schools.

The following are examples of what the participants shared in the focus group and key informants' interviews:

"Christian students, teachers, and administrators are arrested and detained for any peaceful, private religious speech and expression about Christianity. At the same time, Muslim students, teachers, and administrators are permitted to speak freely about Islam to Christian students, teachers, and administrators and to encourage conversion to Islam."

"Christian students are almost excluded from academic activities, sports activities, friendship groups, social activities by many radical Muslim teachers and administrators limit our status and popularity."

"We often hear in classroom discussions the distinction between 'them' and 'us'. 'Them' being Jews and Christians who are the infidels, the enemies, the inferior and second class. 'us' being the Muslims who are the only true believers, and the paradise inhabitants."

"During my elementary and middle school, many radical Muslim students, teachers, and administrators treated me less favorably and socially segregated me. Excluding me from meaningful interactions with at least the moderate Muslim students was very painful. Like millions of Christian students, I had to accept such injustice."

"I remember my Arts teacher in my elementary school was racist and discouraging. She never allowed Christian students to work on projects that explore their own social, ethnic, or religious identities. One day she assigned us a project to draw a place we like to visit and stay in. When I drew a church, she got mad and said, 'This is not what I wanted; you must choose another project."

"Radical Muslim administrators always ignore Radical Muslim teachers' discriminatory interactions with Christian students, and Radical Muslim teachers always ignore the radical Muslim students' discriminatory interactions. This is what happened to me when a Radical Muslim teacher hit me with a stick on my head after insulting me for objecting to what he was saying about my Christian faith. My dad filed a complaint in the school principal's office, but nothing happen till this day."

"My first grade teacher was radical Muslim. He used to make fun of me and my name in almost every class period. He used to call me 'Marcob' that means 'shoe'. I used to correct it and tell him that my name is 'Marco' not 
Marcob. However, he insisted to mispronounce my name to make the Muslim students laugh at me. I hated this teacher because he used to make me cry a lot and to hate school."

"I do remember our Social Studies teacher who was an extremist. He used to call on and validate Muslim students and ignore Christian students during class discussions. For example, when we raise our hands to answer his questions, he does not select us; e.g., let's call on Mohammed again). He seems to have good and correct answers to most of my questions because he is definitely smart."

"Our Radical Muslim high school English teacher always makes inappropriate jokes and uses silly humor in class that degrades Christian students. (e.g., let me tell you a joke about someone named 'Fanous' (a Christian name that means lantern). Once upon a time, there was a man called Fanous who was walking in the dark...."

"In the fourth grade, I had a Christian friend whose name is Saleeb. His name was the source of his daily suffering inside and outside classroom because of his name means 'Cross' and crucifixion is denied in the Qur'an, the Muslim Holy Book. Radical Muslim students, teachers, and school administrators always make fun of his name.... some students even used to spit on him and say we hate your name because it is a lie... . I remember the Arabic teacher giving him a bad grade in one of the assignments requiring us to write on the good qualities of the Islam prophet. His paper was almost perfect in light of the information available to us in the book...the teacher gave him the paper back with $a^{\prime} C^{\prime}$ or something like that saying, 'I failed you because you are lazy and ignorant' ... I deducted some marks for your being ignorant, some marks for being Christian, and some marks because your name is Saleeb (Cross), which I hate."'

"My name 'Botresein' that literary means two Peters and my Christian faith came up in different ways as I interacted with my Muslim classmates and teachers. I remember a teacher telling me that one Botros (One peter) is more than enough. Why are you annoying us with two Peters. I also remember a Muslim classmate telling me that I was good and friendly, but the only bad stuff about me is both my faith and my name."

"I still remember my new Math teacher in my 3rd grade when he asked us to introduce ourselves... when I said I am Hady, he asked for my middle name, and then the last name. I could tell how confused he was when he could not distinguish if I am Christian or Muslim. He continued saying OK, are you Christian or Muslim? I still visualize the surprise on his face." 
Category 3: Impact of Discriminatory Educational Policies, Practices, and Daily Interactions on Christian Students' Mental Health

Research Question 3 asked, "How do the discriminatory educational policies, practices, and daily interactions in the Egyptian K-12 school settings impact Egyptian Christian students' mental health?" The participants of the present study responded in turn and each provided a few responses to the question to express their perception of how the discriminatory educational policies, practices, and daily interactions in the Egyptian K-12 school settings impact their mental health. The following are some of the most commonly described experiences:

1. Feeling powerlessness towards the unjust discriminatory educational policies and the inequality exercised on them.

2. Feeling inferior to their Muslim counterparts.

3. Experiencing frustration and negative emotions regarding the loss of their Coptic language and Christian history and culture.

4. Experiencing isolation, loneliness, and sacrifice.

5. Experiencing anxiety and mild depression.

6. Having low levels of self-esteem.

7. Suffering psychological distress.

8. Experiencing social and emotional difficulties and stress.

9. Feeling hopelessness and helpless.

10. Experiencing negative self-worth, and loss of their Coptic Christian identity.

11. Experiencing a sense of assertiveness in a few situations.

12. Having positive emotions and feelings of strength and power sometimes.

Here are some examples of what the participants shared in the focus group and key informants' interviews:

"The continuing discriminatory practices in the classroom and school made me feel unwanted and unaccepted. This led to feeling inferior to my Muslim classmates."

"The continuing prejudice and injustice exercised on us from radical Muslim students, teachers, and administrators and being helpless and powerless made us accept negative stereotypes and sometimes we do not recognize them."

"The discrimination in the curriculum and textbooks towards Christians enhances the development of our sense of low self-esteem."

"Being segregated by radical Muslim students, teachers, and school administrators motivate us to even re-segregate ourselves and make a corner in the playground of the school as 'our territory'. This enhances our feelings of being isolated, lonely, and our being the escape goat." 
"The different discriminatory practices in the classrooms, school, curriculum, textbooks, and daily interactions make us feel a lot of anxiety and sometimes depression."

"The pain and suffering connected with unmet unrealistic expectations from our society, our parents and our church that we should always obey and be patient make us feel devastated and often result in high level of punitive selfevaluation and dichotomous thinking."

"Neglecting our Coptic history, language and traditions and marginalizing us causes a lot of frustration and negative emotions regarding the loss of our heritage."

"The injustice and inequality when we try to complain or object towards what is happening to us make us feel hopeless that things might get better in the future."

"Our feeling of being powerless is enhanced not only by the discriminatory practices at schools, but also by parents and priests who always repeat passages from the bible that talk about being a slave to all ... . Whoever wants to become great among you mustbe your servant, and whoever wants to be first must be slave of all... . For even the Son of Man did not come to be served, but to serve, and to give his life as a ransom for many."

"I think because there were so few of us in my secondary school (high school), I felt hurt, weak, disrespected, and unwelcomed. I also felt different and proud to be different as a Christian. I have found it to be helpful for me to grow in my relationships with God. I found that to be strengthening and empowering for me."

"I am very grateful for being Christian and grateful to the daily discriminatory interactions from many of Muslim students and teachers due to being Christian and having the name 'Fady' that means 'savior'. Those actions make us work hard... . To be successful, we have to work twice as hard as our Muslim classmates. Although this adds to our sufferings, but it makes us brighter, stronger, and more emotionally intelligent."

\section{Discussion and Conclusion}

The findings of the present study show that Egyptian Christian students are continually suffering from individual, institutional, and structural discriminatory policies and practices reflected in the school curriculum, syllabi, examinations, scholastic and social activities. They also show that the most painful discriminatory practice for Christian students is the discrimination from many of their Muslim peers, teachers, and administrators. Such findings confirm the findings of other 
studies that indicated the suffering of minority students due to individual, institutional and structional discrimination (e.g., Greene et al. 2006, Grossman and Liang 2008, Rivas-Drake et al. 2008, Rosenbloom and Way 2004, Qin et al. 2008). They also show that the Egyptian Christian students are exposed to blatant discrimination that happens most frequently in the form of verbal harassment, bullying, and exclusion by Muslim peers and teachers. These lived experiences that include being stereotyped, calls names, made fun of and excluded from group activities results in negative psychological consequences. These findings are consistent with the findings of many empirical studies on ethnic, racial, and religious discrimination (e.g., Fisher et al. 2000, Rosenbloom and Way 2004).

The findings of the present study also show that discrimination in school settings can be manifested in different forms such as, "stereotypes", "prejudice", "racial micro aggressions". These findings confirm the findings of previous studies (e.g., Brown and Bigler 2005, Cheryan and Monin 2005, Sue 2007). They also show that the frequency of perceived discriminatory policies and practices results in negative health outcomes. Such findings are consistent with the findings of the growing body of research on discrimination and psychological effects (e.g., Byrd and Mirken 2011, Lewis et al. 2015, Kaholokula et al. 2012, Morris 2011, Mossakowski et al. 2017). They also indicate how continued discrimination towards students from racial, ethnic, and religious minorities in school settings results in a variety of negative psychological, physiological, and psychosocial distresses. These findings are also consistent with and confirm the findings of many empirical studies on the effects of discrimination on children and young people's wellbeing (e.g., Coker et al. 2009, Kelly et al. 2012, Mays et al. 2007, Nyborg and Curry 2003, Pachter and Garcia Coll 2009, Paradies 2006b, Priest et al. 2010, Sanders-Phillips 2009, Simons et al. 2002, Szalacha et al. 2003, Williams and Mohammed 2009).

The similarities in the participants' perceptions of their lived experiences with discriminatory educational policies and practices in the Egyptian K-12 school settings were striking. There was a great focus on the discriminatory contents of the curriculum, syllabi, and textbooks. There was a great focus on the hurting discriminatory interaction, negative communications, and stereotyping from many Muslim students, teachers, and administrators, especially the radical ones. The Egyptian school environment is causing both intentional and unintentional hurt to Christian students. Discriminations towards Christian students in the Egyptian K12 school settings is resulting in hostile and unwelcoming classroom and school environments. In most cases, Christian students accept such negative stereotypes, prejudice, injustice, micro and macro aggressions because they are helpless and hopeless and have no support system from the State. To conclude, the findings of this study show internal consistency. The findings show that Christian students suffer continuing discrimination in the Egyptian K-12 school settings. They also show that there was a consensus among the participants that the discriminatory educational policies and practices in the Egyptian K-12 school settings negatively influence their mental health. 


\section{Limitations of the Study}

The findings of this study should be considered in light of several possible limitations. First, the results of this study are drawn from a comparatively small purposive sample of participants (12 Christian high school students). Second, the data in this study come from a self-report instrument which might include intentional misreporting of behaviors and a possibility of socially desirable responses by the participants. Third, my biases and predispositions as a researcherobserver could have an influence on the data collection, analysis, and interpretation of the findings.

\section{Recommendations}

In light of the findings of this study, I recommend the following:

1. The Egyptian ministry of education must review its educational policies and make them inclusive and culturally responsive.

2. The Egyptian K-12 curriculum syllabi, and instructional materials must be reviewed and modified by qualified multicultural experts to reflect the multicultural society.

3. Teachers and administrators, and materials developers must be trained in multiculturalism and diversity.

4. Instruction at schools must acknowledge students' differences as well as their communities.

5. Teachers must validate students' actual identities, classroom practices, and instructional materials.

6. Students must be educated about the diversity of the Egyptian society and the whole world.

7. Equity and mutual respect must be promoted among students, teachers, and administrators.

8. Positive interactions among students, their families, the community, and school must be fostered.

\section{Suggestions for Further Research}

In light of the study findings and recommendations, I am interested in pursuing the following extensions of this research:

1. Replicating this study using quantitative research instruments.

2. Replicating this study for college students.

3. Studying how K-12 Egyptian Christian students cope with discrimination and micro aggressions.

4. Studying how college Egyptian Christian students cope with discrimination and micro aggressions. 
5. Studying how Egyptian Christians cope with discrimination and micro aggressions in the workplace.

\section{References}

Adler N, Rehkopf D (2008) U.S. Disparities in Health: Descriptions, Causes, and Mechanisms. Annual Review of Public Health 29(April): 235-252.

Atta-Alla M (2008) Contemporary Egyptian Family. In T Maundeni, LL Levers, G Jacques (eds) Changing Family Systems: A Global Perspective, 114-126. Gaborone, Botswana: Bay Publishers.

Atta-Alla Monir F (2012) Egypt Education System: A Monocultural Education in a Multicultural Society. Journal of Sociological Research 3(2): 476-488.

Banks JA, Banks CA (2010) Multicultual Education: Issues and Perspectives ( $7^{\text {th }}$ ed) Hoboken, N.J.: John Wiley \& Sons, Inc.

Berg BL (2007) Qualitative Research Methods, $5^{\text {th }}$ ed. Boston, MA: Pearson Education, Inc.

Brown CS, Bigler RS (2005) Children's perceptions of discrimination: A Developmental Model. Child Development, 76: 533-553.

Byrd D, Mirken B (2011) Post Racial? Americans and Race in the Age of Obama. Berkeley, CA: Greenlining Institute.

Central Bureau of Statistics and Mobilization of Egypt (October, 2017) Retrieved from https://bit.ly/2NY6T2R.

Cheryan S, Monin B (2005) Where are you really from?: Asian Americans and Identity Denial. Journal of Personality and Social Psychology 89(5): 717-730.

Cohen MZ, Kahn DL, Steeves RH (2000) Hermeneutic Phenomenological Research: A Practical Guide for Nurse Researchers. Thousand Oaks, CA: Sage.

Coker AL, Hopenhayn C, DeSimone CP, Bush HM, Crofford L (2009) Violence against Women Raises Risk of Cervical Cancer. Journal of Women's Health 18(8): 1179- 1185.

Denzin NK, Lincoln YS (2000) The Discipline and Practice of Qualitative Research. In Denzin and Lincoln (eds) Handbook of Qualitative Research. Thousand Oaks, CA: Sage Publishing.

Dovidio JF, Gaertner SL (2000) Aversive Racism and Selective Decisions: 1989 -1999. Psychological Science 11(4): 315-319.

Egypt 2016 International Religious Freedom Report. Retrieved from https://bit.ly/2D HOIun.

Fisher CB, Wallace SA, Fenton RE (2000) Discrimination Distress during Adolescence. Journal of Youth and Adolescence 29(6): 679-695.

Fiske ST (1998) Stereotyping, Prejudice, and Discrimination. In DT Gilbert, ST Fiske, G Lindzey (eds) Handbook of Social Psychology $4^{\text {th }}$ ed, vol 2, 357-411. New York: McGraw-Hill.

Gay G (2010) Acting on Beliefs in Teacher Education for Cultural diversity. Journal of Teacher Education 61(1-2): 143-152. doi: 10.1177/ 0022487109347320.

Gee GC, Ro A, Shariff-Marco S, Chae D (2009) Racial Discrimination and Health among Asian Americans: Evidence, Assessment, and Directions for Future Research. Epidemiologic Reviews 31(1): 130-151.

Greene M L, Way N, Pahl K (2006) Trajectories of Perceived Adult and Peer Discrimination among Black, Latino, and Asian American Adolescents: Patterns and Psychological Correlates. Developmental Psychology 42(2): 218-238. 
Grossman JM, Liang B (2008) Discrimination distress among Chinese American Adolescents. Journal of Youth and Adolescence 37(1): 1-11.

Guyll M, Matthews KA, Bromberger JT (2001) Discrimination and Unfair Treatment: Relationship to Cardiovascular reactivity among African American and European American Women. Health Psychology 20: 315-325.

Heikal MH (2000) Al-Koutoub: WeghatNazzar; i.e. Books: Viewpoints. Cairo: Hewstone

Huynh VW, Fuligni AJ (2010) Discrimination Hurts: The Academic, Psychological, and Physical Well-being of Adolescents. Journal of Research on Adolescence 20(5): 916-941. doi:10.1111/j.1532-7795.2010 .00670.x

Jorgensen DL (1989) Participant Observation: A Methodology for Human Studies, vol. 15. Thousand Oaks, California: Sage Publications.

Kaholokula JK, Grandinetti A, Keller S, Nacapoy AH, Kingi TK, Mau MK (2012) Association between Perceived Racism and Physiological Stress Indices in Native Hawaiians. Journal of Behavioral Medicine 35(1): 27-37. doi:10.1007/s10865-01 1-9330-z.

Kelly YJ, Becares L, Nazroo J (2012) Associations between Maternal Experiences of Racism and Early Child Health and Development: Findings from the UK Millennium Cohort Study. Journal of Epidemiology and Community Health 67(1): 35-41. http:// dx. doi.org/10.1136/jech-2011-200814.

Kessler RC, Mickelson KD, Williams DR (1999) The Prevalence, Distribution, and Mental Health Correlates of Perceived Discrimination in the United States. Journal of Health and Social Behavior 40(3): 208-230. http://doi.org/10.2307/2676349.

Klonoff EA, Landrine H, Ullman JB (1999) Racial Discrimination and Psychiatric Symptoms among Blacks. Cultural Diversity \& Ethnic Minority Psychology 5(4): 329. http://doi.org/10.1037/1099-9809.5.4.329 42.

Kottak CP (2000) Anthropology: The Exploration of Human Diversity, $8^{\text {th }}$ ed. Boston: McGraw-Hill.

Landrine H, Klonoff EA (1996) The Schedule of Racist Events: A Measure of Discrimination and a Study of its Negative Physical and Mental Health Consequences. Journal of Black Psychology 22(2): 144-168.

Levers LL (2006) Samples of Indigenous Healing: The Path to Good Medicine. International Journal of Disability, Development, and Education 53(4): 479-488.

Lewis TT, Cogburn CD, Williams DR (2015) Self-reported Experiences of Discrimination and Health: Scientific Advances, Ongoing Controversies, and Emerging Issues. Annual Review of Clinical Psychology 11(March): 407-440.

Lincoln Y, Guba E (1985) Naturalistic Inquiry. Thousand Oaks, CA: Sage Publications.

Mays VM, Cochran SD, Barnes NW (2007) Race, Race-based Discrimination, and Health outcomes among African Americans. Annual Review of Psychology 58 (January): 201-205.

McCracken G (1988) The Long Interview. Newbury Park, CA: Sage.

Meyer IH (2003a) Prejudice, Social Stress, and Mental Health in Lesbian, Gay, and Bisexual Populations: Conceptual Issues and Research Evidence. Psychological Bulletin 129(5): 674-697.

Morris JJ (2011) The Stereotyping of American Indians: Where do we Currently Stand at the University Level? The Journal of Multiculturalism in Education 7(3): 1-12.

Mossakowski KN, Wongkaren T, Uperesa FL (2017) It is not Black and White: Discrimination and Distress in Hawai'i. Cultural Diversity and Ethnic Minority Psychology 23(4): 551-560. http://doi.org/10.1037/cdp0000139.

Nyborg VM, Curry JF (2003) The Impact of Perceived Racism: Psychological Symptoms among African American Boys. Journal of Clinical Child and Adolescent Psychology 32(2): 258-266. 
Pachter LM, Garcia Coll C (2009) Racism and Child Health: A Review of the Literature and Future Directions. Journal of Developmental and Behavioral Pediatrics 30(3): 255-263.

Paradies Y (2006a) Defining, Conceptualizing and Characterizing Racism in Health Research. Critical Public Health 16(2): 143-157.

Paradies Y (2006b) A systematic Review of Empirical Research on Self-reported Racism and Health. International Journal of Epidemiology 35(4): 888-901.

Pascoe EA, Smart Richman L (2009) Perceived Discrimination and Health: A Metaanalytic Review. Psychological Bulletin 135(4): 531-554. http://doi.org/10.1037/a00 16059.

Patton MQ (2002) Qualitative Evaluation and Research Methods, $3^{\text {rd }}$ ed. London, UK: Sage.

Priest N, Paradies Y, Stevens M, Bailie R (2010) Exploring Relationships between Racism, Housing and Child Illness in Remote Indigenous Communities. Journal of Epidemiology and Community Health 66(5): 440-447.

Qin DB, Way N, Rana M (2008) Understanding Psychological and Social Adjustment of Chinese American Adolescents at School. New Directions for Child and Adolescent Development 121: 27-42.

Rivas-Drake D, Hughes D, Way N (2008) A Closer Look at Peer Discrimination, Ethnic Identity, and Psychological Well-being among urban Chinese American Sixth Graders. Journal of Youth and Adolescence 37(1): 12-21. http://doi.org/10. 1007/s10964-007-9227-x.

Rosenbloom SR, Way N (2004) Experiences of Discrimination among AfricanAmerican, Asian-American, and Latino Adolescents in an Urban High School. Youth \& Society 35(4): 420-451.

Rubin HJ, Rubin IS (1995) Qualitative Interviewing: The Art of Hearing Data. Thousand Oaks, CA: Sage Publications.

Sanders-Phillips K (2009) Racial Discrimination: A Continuum of Violence Exposure for Children of Color. Clinical Child and Family Psychology Review 12(2): 174-195.

Schmitt MT, Branscombe NR, Postmes T, Garcia A (2014) The Consequences of Perceived Discrimination for Psychological Well-being: A Meta-analytic Review. Psychological Bulletin 140(4): 921-48.

Schulz A, Williams DR, Israel B, Becker A, Parker E, James SA, et al. (2000) Unfair Treatment, Neighborhood Effects, and Mental Health in the Detroit Metropolitan Area. Journal of Health and Social Behavior 41(3): 314-332.

Shukrallah H (1994) The Impact of the Islamic Movement in Egypt. Feminist Review 47(Summer): 15-32.

Simons RL, Murry V, McLoyd V, Lin K-H, Cutrona C, Conger RD (2002) Discrimination, Crime, Ethnic Identity, and Parenting as Correlates of Depressive Symptoms among African American Children: A Multilevel Analysis. Development and Psychopathology 14(2): 371-393.

Sue DW, Capodilupo C, Torino G, Bucceri J, Holder A, Nadal K, Esquilin M (2007) Racial Microaggressions in Everyday Life: Implications for Clinical Practice. American Psychologist 62(4): 271-286.

Szalacha LA, Coll CG, Alarcón O, Fields JP, Ceder I (2003) Discrimination and Puerto Rican Children's and Adolescents' Mental Health. Cultural Diversity and Ethnic Minority Psychology 9(2): 141-155.

Taylor LS, Whittaker CR (2009) Bridging Multiple Worlds: Case Studies of Diverse Educational Communities, $2^{\text {nd }}$ ed. Boston: Pearson Education.

Tummala-Narra P, Claudius M (2013) Perceived Discrimination and Depressive Symptoms among Immigrant-origin Adolescents. Cultural Diversity \& Ethnic 
Minority Psychology 19(3): 257-69.

Utsey SO, Ponterotto JG (1996) Development and Validation of the Index of RaceRelated Stress (IRRS). Journal of Counseling Psychology 43(4): 490-501.

Williams DR, Mohammed SA (2009) Discrimination and Racial Disparities in Health: Evidence and Needed Research. Journal of Behavioral Medicine 32(1): 20-47.

Williams JMG, Watts FN, MacLeod C, Mathews A (1997) Cognitive Psychology and Emotional Disorders, $2^{\text {nd }}$ ed. Chichester, England: Wiley.

Williams DR, Neighbors HW, Jackson JS (2003) Racial/ethnic Discrimination and Health: Findings from Community Studies. American Journal of Public Health 93(Suppl 1): 200-208.

Williams DR, Spencer MS, Jackson JS (1999) Race, Stress, and Physical Health: The Role of Group Identity. In R Contrada, R Ashmore (eds) Self, Social Identity and Physical Health: Interdisciplinary Explorations, vol. 2, 71-100. New York: Oxford University Press.

Williams DR, Yu Y, Jackson JS, Anderson NB (1997) Racial Differences in Physical and Mental Health: Socio-economic Status, Stress and Discrimination. Journal of Health Psychology 2(3): 335-351. 